\title{
Urbanization and Environmental Health, a Safety Concern for Lesotho
}

\author{
Sunny Aiyuk
}

\begin{abstract}
Lesotho, a small country with about two million inhabitants and completely enmeshed within South Africa, is one of the developing countries and emerging/subsistence economies. Faced with ongoing urbanization and the pressures that this puts on the environment, public health and safety concerns are rife, calling for adequate steps to be taken. This is especially given the fact that various industrial and agricultural practices take place in the country and, in particular, given the closeness of the people and animals, increasing the risk of zoonotic diseases.

This research highlighted, through a desk study and site visits, a situational analysis of the current rate at which emerging economies such as Lesotho are becoming modernised through so-called urbanization, and the impacts that this may have on the environment, together with the concomitant burden on public health and general safety. Recommendations for possible economically sustainable interventions are given. Such will ensure that the environment is protected in a sustainable manner and that people stay healthy, while urbanization is on course.
\end{abstract}

Index Terms-Urbanisation, public health, environment, sustainability.

\section{INTRODUCTION}

Urbanization is generally that drive for the state of being or becoming a community or country with urban characteristics, e.g., good paved road networks, pipe-borne water, electricity availability, establishment of different industries, agricultural intensification in mainly a mechanized way, and ongoing construction projects of various scales. Indeed, as development progresses, the cities must be sustainable over the long term [1].

Indeed, an urbanization drive is very noticeable in different countries of the globe, especially in the countries termed developing, where it can easily progress in an inadequately controlled or completely uncontrolled manner, thereby bringing safety into question. Under such conditions, the incidence of injury and disease burden is therefore favoured, together with an unhealthy environment. This is generally consequential to the development of megacities, which are overcrowded cites of the developing world especially [2], [3]. Most of such cities, consequential of urbanization, will also be found in the developing world by 2030.

The consequences of urbanization, controlled or uncontrolled, are many. There is generally a rural exodus

Manuscript received February 1, 2017; revised May 23, 2017.

Sunny Aiyuk is with Department of Environmental Health, Faculty of Health Sciences, National University of Lesotho, PO Roma 180, Lesotho (e-mail: se.aiyuk@nul.1s). with concomitant migration of people from less urban to more urban areas, in order to seize new job opportunities, including foreign nationals who also migrate to seize such opportunities and also create new business. Therefore, although the process of urbanization has many positive outcomes, at present, mankind is faced with a dire environmental degradation and public health challenge arising from it, this being especially the case with developing countries [4]. Under such conditions, for example, industrial activities become quite intensive and lead to many consequences like the discharge of heavy metals, heat and oestrogens, dioxins and other toxins into the environment. Where there is inadequately controlled urbanization, public health safety thus becomes a big issue and, in places like Lesotho, safety concerns are already a rife issue.

In general, in the developing countries, urbanization is usually mainly nodal, i.e., concentrated within big cities, and remains at best not well planned and/or controlled. As has been noted [3], 33\% to $60 \%$ of global population lived in the big cities in the past 60 years, and this is expected to climb to about $70 \%$ in 2050 . Such a trend is found in many developing countries like Lesotho.

Lesotho is a tiny landlocked rugged-terrain country that is completely surrounded by South Africa, with a population of about 2 million. By virtue of its altitude, where the lowest point is about $1400 \mathrm{~m}$ above sea level, the country has a temperate climate, where places are very cold (with snow) in winter than most of other periods of the year, and summers can be quite hot. Temperatures range from $-15^{\circ} \mathrm{C}$ to $35^{\circ} \mathrm{C}$. Following the effects of ongoing environmental degradation and a climate change, the country is getting drier over time from droughts, with the government sending out warnings to communities about desired moves to address the problems, e.g., water conservation (latest in October 2014). The country has a very picturesque geomorphology and scenery, with the rugged terrains whose lithology is of mostly sandstones and clayey sandstones.

Lesotho has a high prevalence of many communicable diseases like HIV\&AIDS (23\%) and Tuberculosis. It is one of the poorest nations of the globe, where communities are mostly rural with subsistence survival, and practicing peasant agriculture and small scale animal rearing, and people live in close contact with the animals. In the country, the female workforce is dominant and, from projections made in this study, things will be so for some time.

The main natural resources of the country are water (that is sold through international trade to South Africa), mohair (traded far abroad), minerals like diamond (traded far abroad $\&$ not quite plentifully found at the moment). The country also provides cheap labour for international brands like Levis 
and Philips.

Lesotho is experiencing rapid urbanization, with Occupational Health and Safety legislation just being formulated at the moment. In the country also, environmental legislation and regulations are fragmented at best, and hardly enforceable until now. Under such conditions, environmental degradation and high disease burden and safety problems become commonplace.

\section{OBJeCTIVE}

The overarching objective of this study was to examine the state of the environment in Lesotho, vis-à-vis ongoing urbanization in the country, in order to raise awareness about the rate at which the environmental health in the country is becoming compromised, and also suggest some corrective measures.

\section{Methodology}

The study was done by direct observation of the environment in Maseru, the capital city, where urbanisation drives are most intense, and other big cities. A review of the literature (desk research) was also made recourse to.

\section{RESUltS AND DisCUSSION}

It should be already pointed out here that the process of urbanization is very admirable, if it goes in line with sustainable planning and control [e.g., 3]. The pros include continuous modernization and industrialization. Also arising from this process is a general responsiveness to community needs, exemplified by job creation, electricity provision, engineered water supply, sanitary upgrade, good roads and other infrastructure, modern health services, access to quality education, among other service provisions. Nevertheless, various negative outcomes concomitant with urbanization in developing countries are well known, since the process remains largely uncontrolled (Figs. 1, 2, 3, 4 and 5).

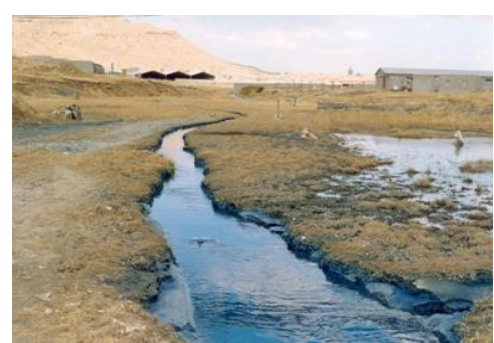

Fig. 1. The Blue River in the Maseru region of Lesotho, laden with industrial dyes and textile fibers.

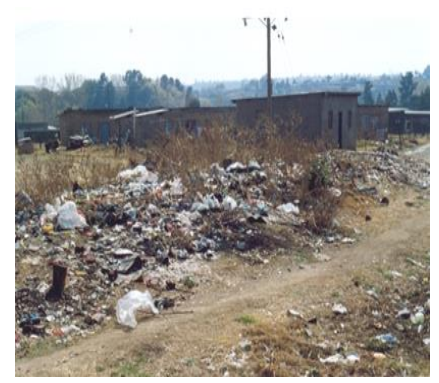

Fig. 2. Indiscriminate littering of the environment with plastics.

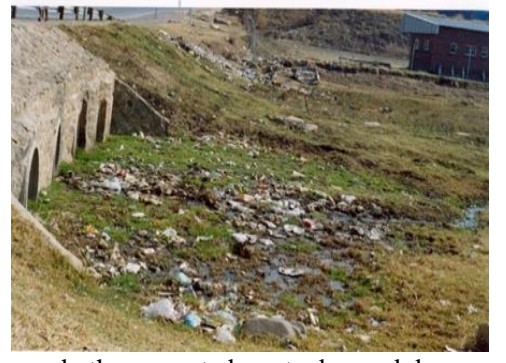

Fig. 3. Plastics and other unsorted waste dumped down a culvert in the Maseru area of Lesotho.

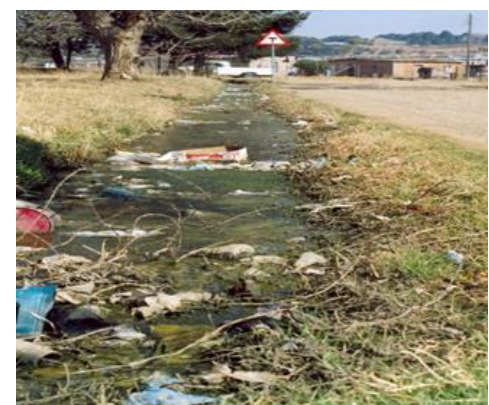

Fig. 4. Deplorable sanitation conditions from using waterways as dumping grounds.

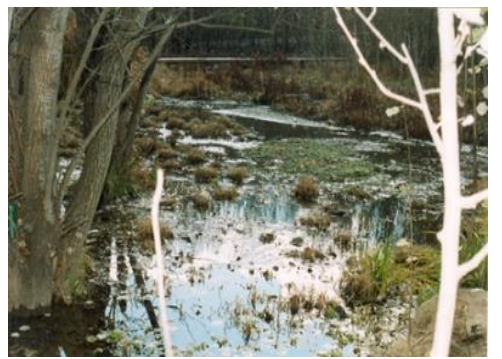

Fig. 5. Eutrophication from dumping wastes and detergents into a water body.

Such consequences span from issues like air, water (surface and ground water) and soil pollution, and an absolute breakdown in sanitation [e.g., 3; 4; 5; 6; 7]. This brings to prominence safety issues, where both the environment itself and the public health of communities are seriously compromised.

Overcrowding in big cities is another problem. In Lesotho, a country whose people mainly rely on subsistence agriculture, one result is that humans and animals get exposed to zoonotic and other disease agents emanating from the air, water, land and contact [3].

So, if the approach to urbanization is not well handled, as is generally the case with Lesotho and many other developing countries, many negative consequences arise. For example the concomitant rural exodus leads to imbalance in rural communities, as was the case with Lesotho when mining activities were booming in South Africa some decades back, and most of males of working age crossed over to the more urbanized country to seek better job opportunities. This has resulted today in the dominant work force in the country being mostly female, as highlighted earlier.

Urbanization has also led to the fringes or peripheries of large cities in many developing countries, e.g., those of Maseru, the capital city of Lesotho, to have peri-urban areas that are mainly slums. The slums arise largely from the fact that, as people leave the rural areas for the big cities, they are met with unbearable costs, and end up at the peripheries of 
the cities, erecting cheap and/or free deplorable shelters and other environments (characterizing the slums) that are a hazard to human health by themselves. Such conditions facilitate disease transmission and compromise general safety. Also, the rendering of the land surface impervious by paving, without good drainage, as is commonly the case in Lesotho, leads to rapid overland flow following the rains and also the creation of floods that easily wash away the slum dwellings and create other problems, even at the centers of the cities.

Another bad outcome of urbanization is deforestation and loss of vegetation. In Lesotho, this has led to cries that include loss of medicinal and other plants, and also loss of wetlands and eutrophication of slow moving water bodies, bringing about oxygen depletion and species imbalance. This brings also a disequilibrium of ecosystems, causing the "pulse" of the environment to become even more irregular, leading to safety concerns like the preponderance of diseases and disease vectors. Also, deforestation leads to encroachment onto forest habitats by humans, in search of new space for development, enhancing thus the proximity between people and forest and other animals that serve as vectors and reservoirs of various diseases. It goes without saying that habitat loss and change also become inevitable for many biota. Another snag is crime increase, and major cities in developing countries are well known for such safety issues, due to ongoing and largely uncontrolled development and livelihood challenges.

Erosion in Lesotho is a well known problem. Vegetation removal and other activities accentuate the loss of surface soil, as, especially, the lithology of the country is mostly of sandstones and clayey sands.

Plastics littered around the environment influence aesthetics negatively. This is very common place in Lesotho (Figs. 2, 3 and 4), where plastics from shopping are still free of charge, and people throw them all around, including down water drainage systems and culverts that usually become blocked, creating a disgusting sight, apart from the drainage problems caused. Such can also create stress (cognitive overload) and other stress related conditions.

In Lesotho, there are also concerns where, due to urban development and following big projects and programs, communities, especially the rural ones, are displaced. Many of the people of these communities believe that such happenings have a lot to do with their safety, as, for example, ties with ancestral values can be lost. This is what can also be termed social change. Urbanization drives in developing countries also leads to serious safety issues like road accidents that are common in big cities of the country and also those of neighbouring South Africa. Another issue is the increased pressure on health facilities in the big cities, where service rendering becomes largely inadequate due to such pressure. So, with an environment where urbanization becomes uncontrollable, can freedom from physical harm and disease, so-called safety, be guaranteed?

With the droughts already talked about, causing shortages in available water resources, Lesotho gets into a panic state, fearing a progressive loss of this resource that is an international trade resource that is sold to South Africa.

The fact that environmental legislation and regulations in the country are fragmented at best and hardly enforceable also leads to undesirable environmental outcomes, like the blue river that flows from textile industries in the main industrial area of the capital city, Maseru (Fig. 1). Industrial activity also leads to the discharge of heavy metals, heat and estrogens into the environment. Such calls for law enforcement and strong advocacy against such environmentally unhealthy discharge.

Indeed, in Lesotho, there is deplorable sanitation in the peri-urban areas that emanate from urbanization pressures. For example, even the VIP latrines that aid in ensuring basic public health, especially in the rural areas of the country, have not been well engineered since conception of the technology [8]. The results are poor sewage, solid waste, health care risk waste and hazardous waste management. The multiplier effect here is pollution of water bodies, the land and the air. It is noteworthy here that communities close to the main industrial area in Maseru often complain of health related problems from industrial discharges, including issues like odour nuisance.

Indeed, the global environment, just like humans, should be looked at as a combination of living organisms [1], and has a 'pulse', the so-called environmental health. This pulse is quite arrhythmic presently, and its irregularity has worsened over time, due to works of nature and, especially, humans, through mainly so-called urbanization (anthropogenic activities). Are people thus safe in such an environment? The answer is clearly "No". This means that the sustainability of the environment becomes more and more compromised, and disease burdens and safety problems will increase. Looking at Lesotho, this concern is rife. So, the earth, although a magnificent reservoir and auto-epurative system, is actually being dragged to its limits by humans, and Lesotho and other fast developing countries, are good examples.

Global warming and climate change, following largely human activities through urbanization, have brought about numerous environmental, health and safety challenges that include the loss of wetlands in many areas of the globe. To corroborate this, it has been indicated that since the twentieth century began, more than half of the world's wetlands have disappeared [9], and some countries lost up to $80 \%$ of their wetlands in the past 30 years leading to the year 2000. This outcome is also linked to eutrophication that causes oxygen deprivation, fish kills, ground water pollution, general ecological imbalance, and the disappearance of important flora and fauna. The environmental changes that arise, many of which have already been discussed above, provide good breeding areas for vectors, adaption of vectors to new areas, and also increased interactions among disease vectors, reservoirs, pathogens and hosts.

Global warming and climate change have led to a plethora of agricultural and safety problems. Examples of such are increased frequency of weather extremes, loss of biodiversity in fragile environments and tropical forests, and loss of fertile coastal lands, due to rising sea levels. Other deleterious effects include longer growing seasons in cool areas, more unpredictable farming conditions in tropical areas, increase in the incidence of agricultural pests, and dramatic changes in the distribution of fish and sea foods [10]. Indeed, it is contended that long term fluctuations in weather patterns, 
following global warming and climate change could have extreme impacts on agricultural production, slashing crop yields and forcing farmers to try to adopt new agricultural practices in response to the altered conditions [10]. Food safety is therefore already at risk, and Lesotho is already in the nexus of these challenges.

In a general sense, as urbanization in developing countries continues at an unprecedented rate and as has been highlighted [3], the combination of high rural exodus and population density [11], poverty, and limited resources makes the developing world megacity an environment which favors the incubation of disease [12], from cholera to tuberculosis to sexually transmitted infections, that in an age of rapid communication can almost instantaneously be propagated to the rest of the world. Vulnerability to terrorism, natural hazards, ecological disasters, war conditions, and food scarcity are also exacerbated in the megacities of the developing world. Such highlight only goes to buttress the findings of this study.

\section{CONCLUSION AND RECOMMENDATIONS}

Urbanization, good as it should be, has dire consequences if not well planned and controlled. As this process is quite rapidly ongoing in Lesotho and without sufficient planning, monitoring and control, there are serious safety concerns that arise from a breakdown of pristine environmental processes. Such safety concerns, quite rife in the country presently, are mainly in connection with occupational and other injury and disease, together with the social change that may arise.

Therefore, through largely uncontrolled urbanization, especially in the urban centers, Lesotho is faced with a dire environmental degradation and safety issues, calling for quick corrective steps to ensure a sustainable environment and protect public health. Environmental policies should be upgraded and enforced in the country and, as there is a general lack of environmental stewardship, all should be brought to task through a well marshalled environmental education and health promotion. It should be generally made to be understood that with environmental issues, humans are all in a "spaceship" called earth, which is the general environment, and there are no passengers in it, with everyone thus being crew and must take charge.

\section{ACKNOWLEDGMENT}

This research was partly sponsored by the National University of Lesotho.

\section{REFERENCES}

[1] T. E. Graedel, "Industrial ecology and the ecocity," The Bridge, vol. 29, no. 4, pp. 10-14, 1999.

[2] United Nations, "Trends in urbanization and the components of urban growth," in Proc. the Symposium on Internal Migration and Urbanization in Developing Countries, New York: United Nations Population Fund, 1998.

[3] G. Bugliarello, "Megacities and the developing world," The Bridge, vol. 29, no. 4, pp. 19-27, 1999.

[4] S. Aiyuk, "Urbanisation "fingerprinting" on environment and health," Lesotho Medical Association Journal, vol. 10, no. 1, pp. 19-23, 2012.

[5] K. M. Rowntree et al., "Changing patterns of erosion in a periurban catchment, Maseru, Lesotho," in Proc. the Vienna Symposium on Sediment and Stream Water Quality in a Changing Environment: Trends and Explanation, August 1991, Vienna, Austria.

[6] T. Hove, "Satellite identifies big cities as major pollution sources," ESA, Europe, 2004.

[7] K. C. Nelson et al., "Forecasting the combined effects of urbanization and climate change on stream ecosystems: from impacts to management options," J. Appl. Ecology, vol. 46, no. 1), pp. 154-163, 2009.

[8] S. E. Aiyuk and M. Tsepa, "Addressing technical flaws in VIP latrines in Lesotho: A community intervention in Qachas' Nek District," presented at the $7^{\text {th }}$ International symposium on "Safety \& Health in Agricultural \& Rural Populations: Global Perspectives, Saskatoon, Saskatchewan, Canada, 2014.

[9] WWF. (2004). Living waters, conserving the source of life: The economic values of the world's wetlands. WWF, Gland, Switzerland.

[10] FAO. (2016). [Online]. Available: http://www.fao.org/NEWS/FACTFILE/FF9721-E.HTM

[11] National Environment Secretariat, "State of the environment in Lesotho 1997," National Environment Secretariat, Maseru, Lesotho, 1999.

[12] R. W. Sutherst, "The vulnerability of animal and human health to parasites under global change," International Journal for Parasitology, vol. 31, pp. 933-948, 2001.

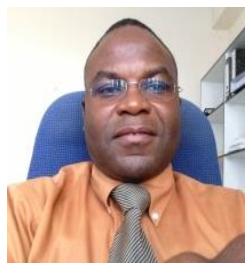

Sunny Aiyuk was born in the city of Kumba in Cameroon, on $20^{\text {th }}$ November, 1962. He holds a Ph.D in environmental technology from the Ghent University, Belgium (2004), a master in advanced management from the Vrije Universiteit Brussel \& Solvay Business School, Belgium (2007). Professor Aiyuk also holds the M.Sc. in water resources engineering from both the Vrije Universiteit Brussel and the Catholic University of Leuven, Belgium (2000) \& an M.Sc. in applied sedimentology \& petroleum geology from the University of Nigeria Nsukka-Nigeria (1993). In addition, he has a B.Sc. in Geology from the University of Yaounde, Cameroon (1985) \& a certificate in prevention \& management of communicable diseases from the African Medical Research Foundation (AMREF), Nairobi, Kenya (2012).

Sunny Aiyuk is presently an associate professor of environmental health at the National University of Lesotho, Lesotho. Prof. Aiyuk is presently the dean of the Faculty of Health Sciences at the National University of Lesotho. He has previously been deputy dean, head of Department of Environmental health, Senior Environmental specialist and Project Environmental engineer. Professor Aiyuk is an expert in Environmental Technology/Engineering, Public Health \& Project Management. He is a global scholar and prolific researcher, and has published widely in the fields of Environmental and Public Health. He is member of various high level committees in Lesotho, such as the National Committee on Waste Management (COWMAN) and the National Committee on Chemicals Management (CHEMAC). 